\title{
Continuous noninvasive ventilation for respiratory failure in patients with amyotrophic lateral sclerosis: current perspectives
}

This article was published in the following Dove Press journal: Degenerative Neurological and Neuromuscular Disease

\author{
Giuseppe Fiorentino' \\ Anna Annunziata' \\ Anna Michela Gaeta ${ }^{2}$ \\ Maurizia Lanza' \\ Antonio Esquinas ${ }^{3}$ \\ 'Division of Respiratory \\ Physiopathology, Monaldi Hospital, \\ Naples, Italy; ${ }^{2}$ Respiratory \\ Department, Arnau de Vilanova and \\ Santa Maria Universitary Hospital, \\ IRBLleida, Lleida, Spain; ${ }^{3}$ Intensive \\ Care Unit, Morales Meseguer \\ Hospital, Murcia, Spain
}

\begin{abstract}
Respiratory failure is a recognized late complication of amyotrophic lateral sclerosis. It is related to the neurological progression of the diseases with the impairment of the respiratory musculature. Survival and quality of life of amyotrophic lateral sclerosis patients is improved by using noninvasive mechanical ventilation. The rate of long-term mechanical ventilation is different within and between countries. Cultural factors, socioeconomic conditions, and physician attitude often influence the decision to start noninvasive ventilation. Technical elements, like the choice of the correct interface, solid caregivers support, and the communication between the patient and the physician are essential for achieving therapeutic goals, especially in the case of continuous treatment. Keywords: noninvasive ventilation, amyotrophic lateral sclerosis, respiratory failure, quality of life, adherence, interface, mouthpiece ventilation
\end{abstract}

\section{Introduction}

The appearance of respiratory failure in amyotrophic lateral sclerosis (ALS) patients depends on the different impairment of the respiratory musculature related to the type of the neurological injury (progressive bulbar palsy or spinal muscular atrophy) and is influenced by the presence of an underlying respiratory pathology (such as, for instance, chronic obstructive pulmonary disease). In the general evaluation of the disease, respiratory symptoms are not easily recognizable ${ }^{1}$ and the alteration of blood gas analysis is evident only in a late stage of the disease or during an acute episode of respiratory failure. ${ }^{2}$ The treatment of complications requires multiple approaches. ${ }^{3}$ The beginning of noninvasive mechanical ventilation and any changes in the therapy must always be shared with the patient to promote adherence to therapy. Because of the progressive worsening of lung function, the patient uses the noninvasive ventilation (NIV) more and more hours a day until total dependence; thus, the questions about invasive ventilation (IV), ie, its timing, relevance, and indications, remain problematic. The survival of patients with ALS under mechanical ventilation experiences a significant variability. Survival of ALS patients is improved if NIV is used for at least 4 consecutive hours during sleep $;{ }^{4}$ sleep hypoxia is significantly corrected by an increase of sleep quality. NIV can relieve symptoms, avoid hospitalizations, and improve quality of life (QoL) of ALS patients. ${ }^{5,6}$

\section{Continuous NIV}

The rate of long-term IMV is substantially different both within and between countries. The factors of this variations are treating physician attitudes, insurance coverage
80131 Naples, Italy

Email giuseppefiorentinol@gmail.it 
(national or private), cultural background of the physician, and the decision the patient or his family makes. ${ }^{3}$ In a crossnational ALS study, the prevalence of long-term mechanical ventilation use was 3\% in a German (121 patients) and 0 in an English sample (50 patients) at a time when home ventilation for ALS patients was not paid for by the national health insurance. ${ }^{7,8}$ The Japanese long-term mechanical ventilation rate, instead, is nearly $45 \% .^{8}$

Thus, the choice of the ALS patients to start long-term mechanical ventilation is not determined by their will only but mostly depends on health insurance coverage. Improved survival, QoL, and cognitive function have been also evaluated by a Cochrane review and a randomized controlled trial., ${ }^{9,10}$ NIV improves QoL in terms of cognitive function, encouraging better sleep architecture and brain oxygenation. ${ }^{10,11}$ In patients with ALS, NIV adherence is very important for survival and QoL benefit. NIV is most often used as a treatment for respiratory problems in ALS, and recent reports about current UK practice have shown an increase of the number of patients treated with NIV. ${ }^{12,13}$

In severe bulbar dysfunction, there is a higher prevalence of poor NIV tolerance, while the presence of hypoventilation symptoms (orthopnea or dyspnea) at the beginning of the NIV initiation is correlated with a good adherence. ${ }^{14-19}$ NIV requires fewer resources, and one of the advantages is that the ALS patients can decide how to continue mechanical ventilation during the evolution of the disease. ${ }^{20}$ In emergency situations, the patients who required admission to the intensive care unit can decide to not undergo invasive ventilation and/ or tracheostomy, as reported in Bach's work. ${ }^{20} \mathrm{NIV}$ is always preferred in the initial phase. The possibility of stopping the NIV and removing the interface, even for a few minutes, is generally better accepted by the patient. Furthermore, NIV can be managed in a simpler way at the patient's home. Some decisions about invasive ventilation should be taken before intensive care unti admission. Data in the literature about use of noninvasive continuous mechanical ventilation is conflicting, probably due to the heterogeneity of the population of patients treated in different studies. In the years following the publication of the American Academy of Neurology Practice Parameters in 1999, there has been an increase of NIV use in neuromuscular diseases. ${ }^{21}$

A significant difference in median survival time in patients who chose early NIV followed by IMV has been found. Over the years, the clinical practice has been improved thanks to the good decision-making process. The respiratory therapy unit works only with the domestic mechanical ventilation, and it results in a good adherence to the forms of ventilation; consequently, survival time has improved..$^{23-26}$ Some authors found only a few months of difference in survival time between patients who underwent NIV with respect to patients without treatment. Patients who accepted NIV and IMV therapy were younger and more motivated to explore all life-prolonging possibilities. ${ }^{27}$ Patients admitted to respiratory ALS specialized centers had longer survival times, unlike those admitted into neurology care units. In fact, subjects attending the tertiary ALS centers were more likely to undergo NIV. ${ }^{23}$ According to patient age, there was a significant difference in survival time at the time of starting NIV. In fact, the use of NIV and its outcome are heavily related to demographic and personal factors. In different countries, young male patients frequently choose the use of NIV followed by IMV. ${ }^{24-27}$ However Chiò et al report differences between the Health System Italian National ALS patient's treatment from the United States one. ${ }^{23}$ In fact, in Italy the ventilation interventions and the home support are provided free of charge and are not dependent on patient's social status and educational level. They also found that NIV was more frequently used by married patients, who also had a longer survival after NIV than nonmarried patients. The presence of family members promotes patient's support and specialized clinical interventions, producing positive effect on patient care and survival (Figure 1). ${ }^{23}$ In a cohort of 403 patients with ALS, only $36.2 \%$ utilized NIV. ${ }^{29}$ This underutilization was clearly expressed by Jackson et al, ${ }^{28}$ in 2006 . Also, according to a Canadian study done in 2010 , only $18.3 \%$ of patients with ALS make use of NIV and $1.5 \%$ use invasive mechanical ventilation by tracheostomy. This data was explained by intolerance, by the machine/patient asynchronies, and by difficulty of access to health care professionals.

\section{Interface for continuous NIV}

Today there are many types of masks available for NIV. Full-face and nasal masks are most commonly used; also,

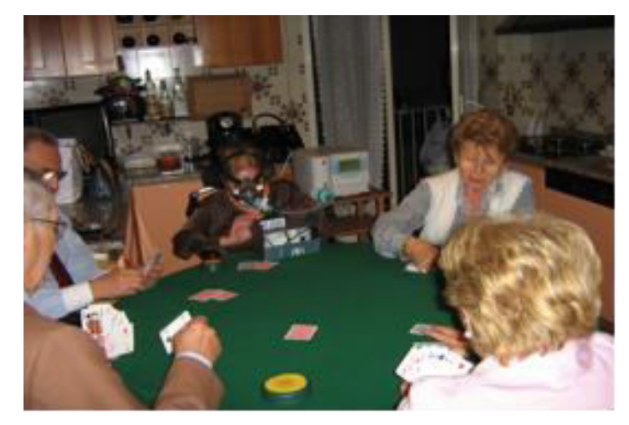

Figure I A patient with ALS in NIV during activities of daily life. Abbreviations: ALS, amyotrophic lateral sclerosis; NIV, noninvasive ventilation. 
new full-face masks with minimal contact and nasal pillows can be used to promote adhesion to NIV. As an alternative to nasal or oronasal masks, a possible option is represented by the total face mask and mouthpiece. Despite the wide availability of models and cuts, the choice of the adequate masks is often very difficult, especially in the patient who undergoes NIV for several hours a day, due to the possible complications that one should try to avoid. Data from a randomized controlled trial showed that the use of NIV in acute hypercapnic respiratory failure using facial or nasal masks leads to the correction of all respiratory parameters, regardless of the interface used. The only difference was that air leaks were more common when using a nasal mask. ${ }^{30}$ At the moment, there are no randomized studies about the use of nasal and oronasal masks. Typically, nasal masks are used in chronic respiratory failure, while oronasal masks are often used in emergencies. This is done to reduce leakage in the mouth, with implications on the efficacy of ventilation. ${ }^{31}$ Until now, causes of upper airway obstruction during NIV were to be due to nasal obstruction, pharyngeal collapse, and/or glottal closure. Vrijsen et $\mathrm{al}^{32}$ described the worsening of apnea and increased desaturation with the use of a nasal mask during NIV. The mechanism of worsening of apnea is probably related to backward movement of the tongue from the air blown into the mouth. This mechanism is caused by muscular hypotonia, especially during sleep when there is loss of voluntary muscle control, resulting in asynchrony and loss of efficacy of NIV with destructive sleep patterns, hypoxemia, and hypercapnia. Asynchrony is commonly associated with leak. Therefore, leaks are reduced by improving the coordination between the patient and the NIV: this is achieved using a suitable interface and a ventilator with a good leak compensation system. The continuous use of NIV causes severe decubitus (Figure 2). The appearance of severe skin lesions could be a factor of poor adherence,

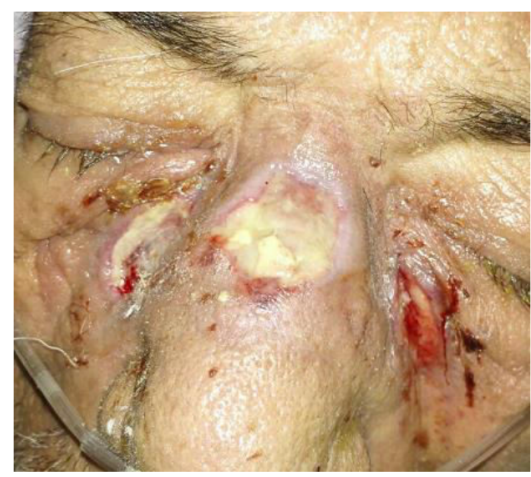

Figure 2 Severe nasal decubitus. especially in ventilator-dependent patients. In fact, the use of different interfaces to favor a variation of pressure points should be evaluated. The choice of correct interface plays a decisive role in reducing complications (such as excessive pressure, skin lesions, leaks, and claustrophobia) that interfere with continuous treatment. ${ }^{33,34}$ Facial masks are the most commonly favored, but their use may be limited by anxiety and painful skin lesions. Nasal pillows can also be used to promote adhesion to NIV, but they may be accompanied by a reduced seal at high pressures $\left(>15 \mathrm{cmH}_{2} \mathrm{O}\right)$ and nasal irritation. ${ }^{35}$ As an alternative to nasal or oronasal masks, especially in the presence of skin lesions or in order to increase the patient comfort, a possible option is represented by the total face mask. The total face mask overcomes some problems related to other interfaces because it seals around the facial features. ${ }^{36}$ Some authors describe the advantageous characteristics of the total face mask as follows: easy adjustment on the patient's facial features and flexibility of use with several modes and ventilatory parameters. Also, a total face mask reduces dead space. ${ }^{35}$ In previous studies, ${ }^{37,38}$ it was shown that a total face mask promoted the adaptation to NIV in ALS patients who were 24-hour ventilator-dependent, leading to reducing skin lesions in the presence of decubitus. Also, it allows hypercapnia level control and prevents endotracheal intubation (Figure 3). Mouthpiece ventilation modes have been recently introduced in commercially available portable ventilators and, for this reason, in the last years the interest in this new mode of ventilation has been growing.

The possibility to change the interfaces during the different daily activities represents an important improvement of QoL and adherence to treatment in patients who need continuous NIV. ${ }^{39}$ The mouthpiece improves the social aspects of the patients, allowing them to speak and eat. Moreover,

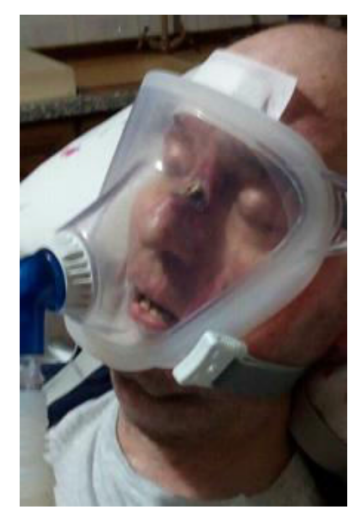

Figure 3 ALS patient in long-term mechanical ventilation treated with total face mask.

Abbreviation: ALS, amyotrophic lateral sclerosis. 
the patient can remove the mouthpiece to cough. Most of the patients hold the mouthpiece near the mouth by a metal support arm attached to the bed or to the wheelchair (Figure 4). NIV via mouthpiece is becoming the most important method of daytime ventilatory support.

Some authors used mouthpiece ventilation during daytime hours alternating with nasal ventilation during sleep while weaning from the tracheostomy tube. ${ }^{40}$ However, in the case of pronounced facial muscle weakness and in cases where it was not possible to have a mouthpiece, it is better to use the nasal mask for diurnal NIV, rather than to undergo tracheostomy. If possible, mouthpiece should be preferred, because there is no risk of skin lesions, gastric distention, or conjunctivitis, and this is also well tolerated by patients with claustrophobia.

The mouthpiece could be considered during the NIV adaptation phase. ${ }^{39}$ Bédard and $\mathrm{McKim}^{41}$ recently studied the utilization of daytime mouthpiece ventilation in an ALS population using 24-hour NIV. They confirm the importance of preserved bulbar function and the ability to generate adequate peak cough flow for effective mouthpiece ventilation for survival.

Despite its practicality and effectiveness, mouthpiece ventilation is rarely used in patients with ALS. ${ }^{41}$

In patients showing poor NIV tolerance with oronasal and nasal masks, mouthpiece ventilation should always be considered. In patients using NIV many hours a day or in the case of skin lesions, eye irritation, or gastric distention, mouthpiece ventilation should be also considered. The use of mouthpiece ventilation combined with other interfaces leads to an improvement in QoL and greater adherence in neuromuscular patients.

\section{QoL in continuous NIV}

The meaning of QoL is the result of objective and subjective indicators and its description is not simple. In patients

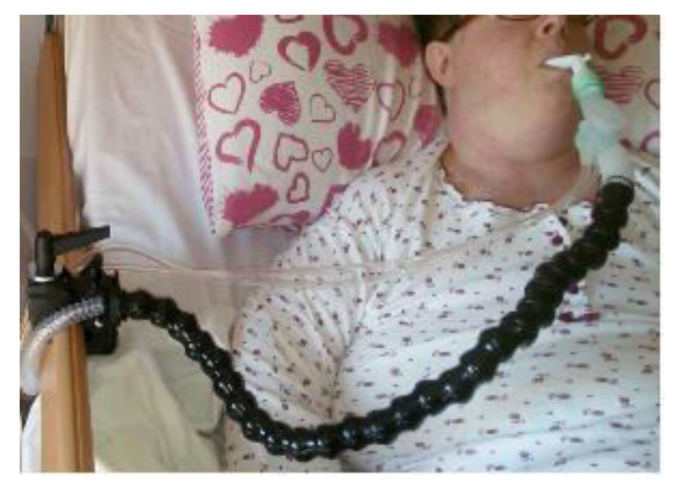

Figure $4 \mathrm{ALS}$ patient during MPV with arm attached to the bed.

Abbreviations: ALS, amyotrophic lateral sclerosis; MPV, mouthpiece ventilation. with ALS, QoL is closely linked to disability but also to the characteristics of the individual as well as to cultural and social factors. Human dignity can be described as the ability to exercise free will and choice. The concept of dignity of life (DoL) is linked to the principle of autonomy in biomedical ethics: that is, it is always the patient who decides and who has the final say. In patients with ALS, noninvasive mechanical ventilation leads to an increase in survival time and also in the QoL. ${ }^{42,43}$ Some studies have shown that the QoL in patients with ALS is not related to physical function. ${ }^{44-46}$ However, the QoL of ventilator-dependent ALS patients has not been extensively studied. Rousseau et $\mathrm{al}^{47}$ described that both nonventilated locked-in-state patients and invasively ventilated patients showed no difference in QoL score with the McGill scale and the Short form 36 scale. They concluded that, in patients with the same level of dependence, invasive mechanical ventilation does not affect QoL. Many studies indicate that approximately $44 \%-75 \%$ of ALS patients show signs and symptoms typical of depressive syndromes. Furthermore, $15 \%$ of them had severe depressive symptoms. ${ }^{48,49}$ Prevalence of depression does not show differences between invasively ventilated and nonventilated patients or between IV and NIV patients. This data is coherent with Kübler et $\mathrm{al}^{50}$ and Hazenberg et $\mathrm{al}^{51}$ who indicated that in some patients with ALS, QoL did not improve after 6 months of NIV. Although blood gases improved certain domains such as social relationships, physical and social functioning showed a downregulation compared to the initial treatment values. ${ }^{51}$ It has been demonstrated, examining 43 patients with ALS who had disease progression, that the DoL was preserved while the QoL worsened. The preservation of the DoL can be due to various factors including the presence and support of caregivers, psychologists, and support that prepares the patient for the progression of the disease. A very important role is played by encouraging communication on end-of-life issues. Therefore, together with the QoL, the DoL is also a very important target for the care and the correct management of the patients with ALS. ${ }^{52}$ Current US and European guidelines recommend that ALS patients make correct informed choices regarding the IMV and palliative care. ${ }^{22,10}$ This must happen starting from the early stages of the diagnosis of ALS and is especially needed when NIV therapy is no longer tolerated or when the progression of the disease makes it ineffective.

\section{Other considerations}

When ALS affects the ventilatory muscles, respiratory failure occurs and patients become dependent on ventilatory treatment. Untreated respiratory failure generally leads to death, 
and actually there are no treatments able to stop the progression of the disease. ${ }^{50}$ In recent years, the management of patients with ALS has significantly changed, especially thanks to the technological evolution of the commercially available portable ventilators. These ventilators are well tolerated and are available for both hospital and home treatments. NIV in patients with ALS is supported by numerous studies showing that their impact on QoL is favorable. ${ }^{8,51,52}$ Furthermore, some authors found that NIV improved survival time in a cohort of 43 patients with ALS. ${ }^{51}$ In contrast to previously published case series, Chadwick et a ${ }^{53}$ showed that 14 out of 30 patients with motor neuron disease were successfully weaned from tracheostomy ventilation, although all had continuing requirements for NIV. ${ }^{54-56}$ The overall survival after hospital discharge was $57 \%$, with 1 year survival of $43.3 \%$. Survival from the initiation of ventilatory support was similar for patients treated with emergency intubation and for those who started elective NIV. No difference in mortality was observed between patients weaned and ventilated with tracheotomy, but a higher percentage of those weaned to NIV were discharged home. Most of the weaned patients only required NIV overnight. No data is available about QoL in patients weaned to NIV. These results have shown that many patients who can be successfully weaned to NIV have an overall survival comparable to that for patients starting NIV in an elective manner.

In ALS patients following acute respiratory failure and intubation, the prognosis is not always characterized by complete ventilator dependence. It is necessary to evaluate every single case. The possibility of tracheotomy should be known by patients with ALS, in any case. The patient must be able to choose before critical events occur. ${ }^{57,58}$ Some studies have shown that the having young children in the family and the patient's age are predictors for the continuation of tracheotomy treatment. ${ }^{59}$ The desire to live is greater in patients who choose long-term mechanical ventilation. There are no evidences that religious faith and spirituality contribute to the decision. Patients who choose IMV expect faithfully a definitive therapy for ALS, and so ventilatory treatment gives them more time to wait for future treatment. Mild emotional lability was reported for $44 \%$ patients who later died, and 29\% who later opted for IMV.

A modest decline in overall life satisfaction together with a continued desire to live was observed over nearly 3 years after IMV in severely limited patients whose communication capacity was generally minimal and whose illness continued to progress. Both NIV and IMV, as long-term ventilation, can result in a high burden on patients and health professionals resulting in patient's desire to withdraw from ventilation therapy. Factors contributing to withdrawal of long-term ventilation (WLTV) are the load of care, the loss of interest, the loss of social life, or the loss of ability to communicate through an ALS-related ophthalmoplegia. Kettemann et $\mathrm{al}^{60}$ described that WLTV is not realized early enough in ALS ventilation therapy. The patients' wish for WLTV emerges after $>1$ year into NIV. WLTV in NIV occurs more frequently when the mask ventilation treatment option is unsatisfactory and the decision between the transition to palliative care at the end of life and the IMV may be necessary. In patients with IMV, WLTV happens significantly later, on average 34 months after initiation of IMV. However, in some cases, the decision for WLTV may occur some days after the start of ventilation therapy or after several years of NIV or IMV, eg, up to 12 years in patients evaluated by Kettemann et al. ${ }^{60}$ Therefore, the ventilation period appears to be a nondecisive element in the decision in favor of or against WLTV. Furthermore, it is not possible to deduce decisive information from the age, sex, and duration of the patients' illness. ${ }^{60}$

\section{Conclusion}

ALS is a complex disease. The diagnosis can take several months, and the course of the disease is very variable. Patients are always heavily dependent on medical care. It is necessary to establish optimal communication between physicians and patients with ALS in order to make appropriate decisions on long-term mechanical ventilation. Most of the decisions about this topic are often taken in emergency situations and in the absence of anticipated directives. For patients who choose continuous mechanical ventilation, physicians should ask for IMV limits and encourage completion of written directives that indicate patient preference for long-term mechanical ventilation shutdown, as if they wish to stop mechanical ventilation under certain circumstances some will at that point of time be unable to communicate. ${ }^{61}$ The presence of family members is very important, as described, because patients who have a reason to live want long-term mechanical ventilation. On the basis of knowledge level available today, if respiratory deficit is severe and NIV is ineffective, the alternative to NIV or death is invasive ventilation. This condition can only be effectively supported by a multidisciplinary team of specialists who make decisions together with patients and caregivers, respecting the will and dignity of the person.

\section{Disclosure}

The authors report no conflicts of interest in this work. 


\section{References}

1. de Carvalho M, Matias T, Coelho F, Evangelista T, Pinto A, Luís ML. Motor neuron disease presenting with respiratory failure. J Neurol Sci. 1996;139(Suppl):117-122.

2. Wijesekera LC, Leigh PN. Amyotrophic lateral sclerosis. Orphanet journal of rare diseases. 2009;4(1):3.

3. Neudert C, Oliver D, Wasner M, Borasio G. The course of the terminal phase in patients with amyotrophic lateral sclerosis. $J$ Neurol. 2001;248:612-616.

4. Bourke SC, Tomlinson M, Williams TL, Bullock RE, Shaw PJ, Gibson GJ. Effects of non-invasive ventilation on survival and quality of life in patients with amyotrophic lateral sclerosis: a randomised controlled trial. Lancet Neurol. 2006;5(2):140-147.

5. Bach JR. Amyotrophic lateral sclerosis: prolongation of life by noninvasive respiratory aids. Chest. 2002;122(1):92-98.

6. Rudnicki S, McVey AL, Jackson CE, Dimachkie MM, Barohn RJ. Symptom Management and End of Life Care. Neurologic clinics. 2015;33(4):889.

7. Borasio GD, Gelinas D, Yanagisawa N. Mechanical ventilation in amyotrophic lateral sclerosis: a cross-cultural perspective. J Neurol. 1998;245(Suppl 2):S7-S12.

8. Moss AH, Casey P, Stocking CB, Roos RP, Brooks BR, Siegler M. Home ventilation for amyotrophic lateral sclerosis patients: outcomes, costs and patient, family, and physician attitudes. Neurology. 1993;43(2):438-443.

9. Radunovic A, Annane D, Jewitt K, Mustfa N. Mechanical ventilation for amyotrophic lateral sclerosis/motor neuron disease. Cochrane Database Syst Rev. 2009;4:CD004427.

10. Andersen PM, Abrahams S, Borasio GD, et al; EFNS Task Force on Diagnosis and Management of Amyotrophic Lateral Sclerosis. EFNS guidelines on the clinical management of amyotrophic lateral sclerosis (MALS) - revised report of an EFNS task force. Eur J Neurol. 2012;19(3):360-375.

11. Lyall RA, Donaldson N, Fleming T, et al. A prospective study of quality of life in ALS patients treated with non-invasive ventilation. Neurology. 2001;57(1):153-156.

12. O'Neill CL, Williams TL, Peel ET, et al. Non-invasive ventilation in motor neuron disease: an update of current UK practice. $J$ Neurol Neurosurg Psychiatry. 2012;83(4):371-376.

13. Dreyer P, Lorenzen CK, Schou L, Felding M. Survival in ALS with home mechanical ventilation noninvasively and invasively: a 15-year cohort study in west Denmark. Amyotroph Lateral Scler Frontotemporal Degener. 2014;15(1-2):62-67.

14. Bourke SC, Bullock RE, Williams TL, Shaw PJ, Gibson GJ. Noninvasive ventilation in ALS: indications and effect on quality of life. Neurology. 2003;61(2):171-177.

15. Aboussouan LS, Khan SU, Meeker DP, Stelmach K, Mitsumoto H. Effect of noninvasive positive-pressure ventilation on survival in amyotrophic lateral sclerosis. Ann Intern Med. 1997;127(6):450-453.

16. Coco DL, Marchese S, Corrao S, Pesco MC, La Bella V, Piccoli F, Coco AL. Development of chronic hypoventilation in amyotrophic lateral sclerosis patients. Respir Med. 2006;100(6):1028-1036.

17. Lo Coco D, Marchese S, Pesco MC, La Bella V, Piccoli F, Lo Coco A. Noninvasive positive-pressure ventilation in ALS: predictors of tolerance and survival. Neurology. 2006;67(5):761-765.

18. Vandenberghe N, Vallet AE, Petitjean T, et al. Absence of airway secretion accumulation predicts tolerance to noninvasive ventilation in ALS. Respir Care. 2013;58(9):1424-1432.

19. Farrero E, Prats E, Povedano M, Martinez-Matos JA, Manresa F, Escarrabill J. Survival in amyotrophic lateral sclerosis with home mechanical ventilation the impact of systematic respiratory assessment and bulbar involvement. Chest. 2005;127(6):2132-2138.

20. Bach JR. Amyotrophic lateral sclerosis. Communication status and survival with ventilatory support. Am J Phys Med Rehabil. 1993;72:343-349.
21. Escariwbill J, Estopa R, Farrero E, Monasterio C, Manresa F. Long-term mechanical ventilation in amyotrophic lateral sclerosis. Respir Med. 1998;92(3):438-441.

22. Miller RG, Rosenberg JA, Gelinas DF, et al. Practice parameter: the care of the patient with amyotrophic lateral sclerosis (an evidence based review). Report of the Quality Standards Subcommittee of the American Academy of Neurology:ALS Practice Parameters Task Force. Neurology. 1999;52:1311-1323.

23. Chiò A, Calvo A, Moglia C, et al. Non-invasive ventilation in amyotrophic lateral sclerosis: a 10-year population based study. J Neurol Neurosurg Psychiatry. 2012;83(4):377-381.

24. Chiò A, Calvo A, Ghiglione P, et al; PARALS. Tracheostomy in amyotrophic lateral sclerosis: a 10-year population-based study in Italy. J Neurol Neurosurg Psychiatry. 2010;81(10):1141e3.

25. Sancho J, Servera E, Diaz JL, Banuls P, Marin J. Home tracheotomy mechanical ventilation in patients with amyotrophic lateral sclerosis: causes, complications and 1-year survival. Thorax. 2011;66(11): 948-952.

26. Ritsma BR, Berger MJ, Charland DA, et al. NIPPV: prevalence, approach and barriers to use at Canadian ALS centres. Can J Neurol Sci. 2010;37(1):54-60.

27. Tollefsen E, Midgren B, Bakke P, Fondenes O. Amyotrophic lateral sclerosis: gender differences in the use of mechanical ventilation. Eur J Neurol. 2010;17(11):1352-1357.

28. Jackson CE, Lovitt S, Gowda N, Anderson F, Miller RG. Factors correlated with NPPV use in ALS. Amyotroph Lateral Scler. 2006;7(2):80-85.

29. Martínez D, Sancho J, Servera E, Marín J. Tolerance of volume control noninvasive ventilation in subjects with amyotrophic lateral sclerosis. Respir Care. 2015;60(12):1765-1771.

30. Girault C, Briel A, Benichou J, et al. Interface strategy during noninvasive positive pressure ventilation for hypercapnic acute respiratory failure. Crit Care Med. 2009;37(1):124-131.

31. Vrijsen B, Testelmans D, Belge C, Vanpee G, Van Damme P, Buyse B. Patient-ventilator asynchrony, leaks and sleep in patients with amyotrophic lateral sclerosis. Amyotroph Lateral Scler Frontotemporal Degener. 2016;17(5-6):343-350.

32. Vrijsen B, Buyse B, Belge C, Testelmans D. Upper airway obstruction during noninvasive ventilation induced by the use of an oronasal mask. J Clin Sleep Med. 2014;10(9):1033-1035.

33. Garuti G, Nicolini A, Grecchi B, Lusuardi M, Winck JC, Bach JR. Open circuit mouthpiece ventilation: concise clinical review. Rev Port Pneumol. 2014;20(4):211-218.

34. Nava S, Navalesi P, Gregoretti C. Interfaces and humidification for noninvasive mechanical ventilation. Respir Care. 2009;54(1):71-84.

35. Roy B, Cordova FC, Travaline JM, D’Alonzo GE Jr, Criner GJ. Full face mask for noninvasive positive-pressure ventilation in patients with acute respiratory failure. J Am Osteopath Assoc. 2007;107(4): 148-156.

36. Antonelli M, Conti G, Pelosi P, et al. New treatment of acute hypoxemic respiratory failure: noninvasive pressure support ventilation delivered by helmet - a pilot controlled trial. Crit Care Med. 2002;30(3):602-608.

37. Pisani L, Carlucci A, Nava S. Interfaces for noninvasive ventilation: technical aspects and efficiency. Minerva Anestesiol. 2012;78:1154-1161.

38. Belchior I, Goncalves MR, Winck JC. Continuous noninvasive ventilation delivered by a novel total face mask: a case series report. Respir Care. 2012;57(3):449-453.

39. Fiorentino G, Annunziata A, Cauteruccio R, Frega GS, Esquinas A. Mouthpiece ventilation in Duchenne muscular dystrophy: a rescue strategy for noncompliant patients. J Bras Pneumol. 2016;42(6):453-456.

40. Bach JR, Bakshiyev R, Hon A. Noninvasive respiratory management for patients with spinal cord injury and neuromuscular disease. Tanaffos. 2012;11(1):7-11.

41. Bédard ME, McKim DA. Daytime mouthpiece for continuous noninvasive ventilation in individuals with amyotrophic lateral sclerosis. Respir Care. 2016;61(10):1341-1348. 
42. Kleopa KA, Sherman M, Neal B, Romano GJ, Heiman-Patterson T. Bipap improves survival and rate of pulmonary function decline in patients with ALS? J Neurol Sci. 1999;164(1):82-88.

43. Piepers S, van Den Berg JP, Kalmijn S, et al. Effects of noninvasive ventilation on survival, quality of life, respiratory function and cognition: a review of the literature. Amyotroph Lateral Scler. 2006;7(4): 195-200.

44. Goldstein LH, Atkins L, Leigh PN. Correlates of quality of life in people with motor neuron disease (MND). Amyotrop Lateral Sler Other Motor Neuron Discord. 2002;3:123-129.

45. Simmons Z, Bremer BA, Robins RA, Walsh SM, Fischer S. Quality of life in ALS depends on factors other than strength and physical function. Neurology. 2000;55(3):388-392.

46. Lo Coco G, Lo Coco D, Cicero V, et al. Individual and health-related quality of life assessment in amyotrophic lateral sclerosis patients and their caregiver. J Neurol Sci. 2005;238(1-2):11-17.

47. Rousseau MC, Pietra S, Blaya J, Catala A. Quality of life of ALS and LIS patients with and without invasive mechanical ventilation. $J$ Neurol. 2011;258(10):1801-1804.

48. Lou JS, Reeves A, Benice TH, Sexton G. Fatigue and depression are associated with poor quality of life in ALS. Neurology. 2003;60(1): $122-123$.

49. Stromberg SF, Weiss DB. Depression and quality of life issues in patients with amyotrophic lateral sclerosis. Curr Treat Options Neurol. 2006;8(5):410-414.

50. Kübler A, Winter S, Ludolph AC, Hautzinger M, Birbaumer N. Severity of depressive symptoms and quality of life in patients with amyotrophic lateral sclerosis. Neurorehabil Neural Repair. 2005;19(3): 182-192.

51. Hazenberg A, Kerstjens HAM, Prins SCL, Vermeulen KM, Wijkstra PJ. Is chronic ventilatory support really effective in patients with amyotrophic lateral sclerosis? J Neurol. 2016;263(12):2456-2461.
52. Martínez-Campo Y, Homedes C, Lazaro A, et al. Observational study of patients in Spain with amyotrophic lateral sclerosis: correlations between clinical status, quality of life, and dignity. BMC Palliat Care. 2017;16(1):75

53. Chadwick R, Nadig V, Oscroft NS, Shneerson JM, Smith IE. Weaning from prolonged invasive ventilation in motor neuron disease: analysis of outcomes and survival. J Neurol Neurosurg Psychiatry. 2011;82(6):643-645.

54. Rabkin JG, Albert SM, Tider T, et al. Predictors and course of elective long-term mechanical ventilation: A prospective study of ALS patients Amyotroph Lateral Scler. 2006;7(2):86-95.

55. Gruis KL, Lechtzin N. Respiratory therapies for amyotrophic lateral sclerosis: a primer. Muscle Nerve. 2012;46(3):313-331.

56. Sanjuán-López P, Valiño-López P, Ricoy-Gabaldón J, Verea-Hernando H. Amyotrophic lateral sclerosis: impact of pulmonary follow-up and mechanical ventilation on survival. A study of 114 cases. Arch Bronconeumol. 2014;50(12):509-513.

57. Bradley MD, Orrell RW, Clarke J, et al. Outcome of ventilatory support for acute respiratory failure in motor neurone disease. $J$ Neurol Neurosurg Psychiatry. 2002;72(6):752-756.

58. Shoesmith CL, Findlater K, Rowe A, Strong MJ. Prognosis of amyotrophic lateral sclerosis with respiratory onset. J Neurol Neurosurg Psychiatry. 2007;78(6):629-631.

59. Moss AH, Oppenheimer EA, Casey P, et al. Patients with amyotrophic lateral sclerosis receiving long-term mechanical ventilation. Advance care planning and outcomes. Chest. 1996;110(1):249-255.

60. Kettemann D, Funke A, Maier A, et al. Clinical characteristics and course of dying in patients with amyotrophic lateral sclerosis withdrawing from long-term ventilation. Amyotroph Lateral Scler Frontotemporal Degener. 2016;18(1-2):53-59.

61. Heritier Barras AC, Adler D, Iancu Ferfoglia R, et al; CeSLA Group. Is tracheostomy still an option in amyotrophic lateral sclerosis? Reflections of a multidisciplinary work group. Swiss Med Wkly. 2013;143:w13830.
Degenerative Neurological and Neuromuscular Disease

\section{Publish your work in this journal}

Degenerative Neurological and Neuromuscular Disease is an international, peer-reviewed, open access journal focusing on research into degenerative neurological and neuromuscular disease, identification of therapeutic targets and the optimal use of preventative and integrated treatment interventions to achieve improved outcomes, enhanced

\section{Dovepress}

survival and quality of life for the patient. The manuscript management system is completely online and includes a very quick and fair peer-review system. Visit http://www.dovepress.com/testimonials.php to read real quotes from published authors. 